\title{
Evaluation of the Insulin-like Growth Factor Receptor Pathway in Patients with Advanced Breast Cancer Treated with Trastuzumab
}

\author{
CHRISTOS CHRISTODOULOU ${ }^{1 *}$, GEORGIOS OIKONOMOPOULOS ${ }^{1 *}$, GEORGIA ANGELIKI KOLIOU ${ }^{2}$, \\ IOANNIS KOSTOPOULOS ${ }^{3}$, VASSILIKI KOTOULA ${ }^{3,4}$, MATTHEOS BOBOS $^{4}$, GEORGE PENTHEROUDAKIS $^{5}$, \\ GEORGE LAZARIDIS ${ }^{6}$, MARIA SKONDRA ${ }^{7}$, SOFIA CHRISAFI ${ }^{4}$, ANGELOS KOUTRAS $^{8}$, \\ DIMITRIOS BAFALOUKOS ${ }^{9}$, EVANGELIA RAZIS ${ }^{10}$, KYRIAKI PAPADOPOULOU $^{4}$, \\ PAVLOS PAPAKOSTAS ${ }^{11}$, HARALAMBOS P. KALOFONOS $^{8}$, DIMITRIOS PECTASIDES ${ }^{7}$, \\ PANTELIS SKARLOS ${ }^{12}$, KONSTANTINE T. KALOGERAS $^{4,13}$ and GEORGE FOUNTZILAS ${ }^{4,14}$ \\ ${ }^{1}$ Second Department of Medical Oncology, Metropolitan Hospital, Piraeus, Greece; \\ ${ }^{2}$ Section of Biostatistics, Hellenic Cooperative Oncology Group, Data Office, Athens, Greece; \\ ${ }^{3}$ Department of Pathology, Aristotle University of Thessaloniki, \\ School of Health Sciences, Faculty of Medicine, Thessaloniki, Greece; \\ ${ }^{4}$ Laboratory of Molecular Oncology, Hellenic Foundation for Cancer Research/ \\ Aristotle University of Thessaloniki, Thessaloniki, Greece; \\ ${ }^{5}$ Department of Medical Oncology, Ioannina University Hospital, Ioannina, Greece; \\ ${ }^{6}$ Department of Medical Oncology, Papageorgiou Hospital, Aristotle University of Thessaloniki, \\ School of Health Sciences, Faculty of Medicine, Thessaloniki, Greece; \\ ${ }^{7}$ Oncology Section, Second Department of Internal Medicine, Hippokration Hospital, Athens, Greece; \\ ${ }^{8}$ Division of Oncology, Department of Medicine, University Hospital, \\ University of Patras Medical School, Patras, Greece; \\ ${ }^{9}$ First Department of Medical Oncology, Metropolitan Hospital, Piraeus, Greece; \\ ${ }^{10}$ Third Department of Medical Oncology, Hygeia Hospital, Athens, Greece; \\ ${ }^{11}$ Oncology Unit, Hippokration Hospital, Athens, Greece; \\ ${ }^{12}$ Department of Radiotherapy, Metropolitan Hospital, Piraeus, Greece; \\ ${ }^{13}$ Translational Research Section, Hellenic Cooperative Oncology Group, Athens, Greece; \\ ${ }^{14}$ Aristotle University of Thessaloniki, Thessaloniki, Greece
}

\begin{abstract}
Background: Trastuzumab is a monoclonal antibody against HER2-positive breast cancer. Despite improving the natural history of the disease, there is a number of patients who are resistant to it, whereas all patients will eventually develop resistance and disease will
\end{abstract}

This article is freely accessible online.

*These Authors contributed equally to this study.

Correspondence to: Christos Christodoulou, MD, Second Department of Medical Oncology, Metropolitan Hospital, 18547 Piraeus, Greece. E-mail: c_christodoulou@yahoo.gr

Key Words: IGF-R, trastuzumab, advanced breast cancer, HER2positive breast cancer, HER2-negative breast cancer. progress. Inconsistent preclinical data show that the IGF-R pathway may contribute to either de novo or acquired resistance to trastuzumab. Materials and Methods: In total, 227 trastuzumab-treated metastatic breast cancer patients were evaluated for IGF-1, IGF-1R, GLP-1R, Akt1, Akt2 Akt3 $m R N A$ expression, and IGF-1R $\alpha, I G F-1 R \beta, I G F-2 R$ protein expression. Results: Only 139 patients were truly HER2positive by central assessment. Among HER2-positive patients, high Akt2 and GLP-1R mRNA expression showed a trend towards higher and lower risk of progression, respectively $(H R=1.83,95 \% C I=0.90-3.72, p=0.094$ and $H R=0.62,95 \% C I=0.36-1.06, p=0.079)$, while high Akt1 and GLP-1R mRNA expression presented a trend towards unfavorable survival $(H R=1.67,95 \% C I=0.93-2.99, p=0.086$ and $H R=1.67,95 \% C I=0.94-2.96, p=0.080)$. Among HER2negative patients, high GLP-1R $m R N A$ expression and negative stromal IGF-1R $\beta$ protein expression showed a trend 
towards worse survival $(H R=2.31,95 \% C I=0.87-6.13$, $p=0.094$ and $H R=2.03,95 \% C I=0.94-4.35, p=0.071$, respectively). In the multivariate analyses, HER2-positive patients with high Akt1 and GLP-1R mRNA expression had $a$ worse survival $(H R=1.86,95 \% C I=1.01-3.43, p=0.045$ and $H R=1.83, \quad 95 \% C I=0.99-3.41, \quad p=0.055, \quad$ respectively). Conclusion: This study revealed a crosstalk between the IGF-R pathway and HER2. There was evidence that high Aktl and GLP-1R mRNA expression might affect survival among HER2-positive metastatic breast cancer patients treated with trastuzumab.

The HER2 receptor is overexpressed in approximately $20 \%$ of breast tumors, as a result of HER2 gene amplification. Overexpression of HER2 is associated with worse prognosis $(1,2)$. Trastuzumab, a recombinant humanized monoclonal antibody against the HER2 protein, has changed the natural history of HER2-positive breast cancer by prolonging overall survival of patients in the metastatic setting and resulting in a higher cure rate in the adjuvant setting $(3,4)$.

Unfortunately, a considerable number of patients with HER2-positive metastatic breast cancer (MBC) does not benefit from trastuzumab (5). Moreover, almost all patients initially responding to trastuzumab-based treatments eventually develop resistance within the first year (6). Mechanisms of primary or secondary resistance to trastuzumab treatment have been described, but have not as yet been clearly elucidated, including PTEN, the PI3K pathway, PIK3CA mutations, dimerization of HER2/HER3, increased VEGF, the TGF-b system and estrogen receptor expression (7-11). In vitro studies in cell lines, as well as clinical studies have suggested that the insulin and insulinlike growth factor receptor (IGF-R)-mediated molecular pathways may be involved in resistance mechanisms to trastuzumab $(8,12-15)$.

The IGF system consists of ligands, receptors and binding proteins $(16,17)$. The IGF ligands comprise IGF-1, IGF-2, insulin and a number of other ligands with undefined biological roles. IGF-1 has autocrine, paracrine and endocrine roles in breast cancer, facilitating disease progression and metastases and supporting the interaction between host and metastatic sites. Especially in HER2-positive disease, the IGF1/HER2 crosstalk occurs through autocrine and paracrine signaling $(18,19)$. The IGF receptors comprise insulin receptor (IR), IGF-1R, IGF-2R and several atypical receptors. IGF-1 and IGF-2 bind to the IGF-1R. IGF-2R binds exclusively to IGF-2. Insulin binds to IR and IGF-1R. Insulin has direct access to the target tissues, in contrast to the IGF-1 and IGF-2, which may be diverted from their receptors by IGF-binding proteins (IGFBPs). The IGF-1R is a transmembrane protein consisting of two alpha $(\alpha)$ and two beta $(\beta)$ subunits. Both the $\alpha$ and $\beta$ subunits are synthesized from a single mRNA precursor. In response to ligand binding, the $\alpha$ chains, which are located extracellularly, induce tyrosine kinase autophosphorylation of the $\beta$ chains that are located intracellularly. This event triggers a cascade of intracellular signaling via the RAS-RAF-MAPK and PI3K-Akt-mTOR pathways, thus promoting cell survival and proliferation. The IGF-2R lacks an intracellular tyrosine kinase domain and therefore does not transduce intracellular mitogenic signals, thus acting mainly as a buffer for IGF-2 bioactivity and its action through IGF-1R $(20,21)$.

In the present study we evaluated IGF-1, IGF-1R, glucagon-like peptide 1 receptor (GLP-1R), Akt1, Akt2 and Akt3 mRNA expression, and IGF-1R $\alpha$, IGF-1R $\beta$ and IGF$2 \mathrm{R}$ protein expression in tumor samples from patients with MBC treated with trastuzumab containing therapy. We evaluated the association of the above markers with HER2 status, ER/PgR status, PIK3CA mutational status, FRAP-1 (mTOR) mRNA expression, and Ki67, TopoIIa, PTEN and phosphorylated mTOR protein expression, as well as with patient outcome.

A total of 227 trastuzumab-treated patients with $\mathrm{MBC}$ and available tumor- tissue for central assessment were included in the current study. All patients were considered to have HER2-positive tumors, as assessed by the investigators in the local hospitals/institutions. However, only 139 patients (61.2\%) were found to be truly HER2-positive by central reevaluation of HER2. Therefore, 88 patients $(38.8 \%)$ with HER2-negative tumors, treated with trastuzumab, were included in the study, as well. This gave us the unique opportunity to study the effectiveness of trastuzumab in HER2-negative MBC patients.

\section{Materials and Methods}

The medical records of all patients with advanced breast cancer treated with trastuzumab-based regimens between March 1999 and January 2010 were reviewed. Eligibility criteria for the study were a: histologically confirmed MBC; b: adequacy of clinical data on patient's history, demographics, tumor characteristics, treatment details (drug dosages, schedule of administration, serious toxicities) and clinical outcome; c: availability of adequate tumor tissue for biological marker evaluation; and d: trastuzumab-based treatment for metastatic disease.

Formalin-fixed paraffin-embedded (FFPE) tumor tissue samples were retrospectively collected from 246 breast cancer patients treated with trastuzumab-based regimens in the metastatic setting, as previously described (22-26). Nineteen cases were excluded for inadequate FFPE tumor tissue, thus decreasing the number of eligible/evaluable patients to 227. A REMARK diagram for the translational research studies is provided in Figure 1. All carcinomas had initially been diagnosed as HER2-positive and thereafter all patients had been treated with trastuzumab. The translational research protocol has been approved by the Bioethics Committee of the Aristotle University of Thessaloniki School of Medicine (Protocol \# 4283; January 14, 2008) under the general title "Investigation of major mechanisms of resistance to treatment with trastuzumab in patients with metastatic breast cancer". All patients included in the 
study after 2005 provided written informed consent for the provision of biological material for future research studies, before receiving any treatment. Waiver of consent was obtained from the Bioethics Committee for patients included in the study before 2005 .

All tumor samples were re-evaluated by immunohistochemistry (IHC) for estrogen receptors (ER), progesterone receptors (PgR), HER2 and the expression of the proliferation marker Ki67, while HER2 status was re-examined by fluorescence in situ hybridization (FISH). Moreover, for the purpose of this study, IGF-1R $\alpha$, IGF-1R $\beta$ and IGF-2R protein expression was examined by IHC, while IGF-1, IGF-1R, GLP-1R, Akt1, Akt2 and Akt3 mRNA expression was evaluated by quantitative reverse transcription-polymerase chain reaction (qRT-PCR). Data from earlier publications by our group, such as Ki67, TopoIIa, PTEN and phosphorylated mTOR protein expression examined by IHC, FRAP-1 (mTOR) mRNA expression evaluated by qRT-PCR and single nucleotide polymorphism (SNP) genotyping performed for the evaluation of PIK3CA mutations were used for associations with the present findings.

Tissue microarrays (TMAs). Representative hematoxylin-eosin stained sections from the tissue blocks were reviewed by a pathologist (M.B.). Seventeen TMA blocks were constructed from the 227eligible cases using a manual tissue microarrayer (Beecher Instruments, Sun Prairie, WI, USA), as previously described (22). For the construction of the TMA blocks, 2 core samples $(1.5 \mathrm{~mm}$ in diameter) were obtained from representative regions of each tumor in the donor blocks. Each TMA block also contained cores from various neoplastic, non-neoplastic and reactive tissues, serving as assay controls. All markers were assessed by IHC or FISH in sections cut from the TMA blocks. Cases not represented, with damaged or inadequate cores on the TMA sections were re-cut from the original blocks if still available and these sections were used for protein and gene analysis, as previously described $(22-25,27)$.

Immunohistochemistry (IHC). Serial 2.5- $\mu$ m thick TMA sections or whole-tissue sections were stained for ER (clone 6F11, Leica Biosystems, Newcastle Upon Tyne, UK), PgR (clone 1A6, Leica Biosystems), HER2 (polyclonal Ab, code A0485, Dako, Glostrup, Denmark) and Ki67 (clone MIB-1, code M7240, Dako), as previously described in detail (28). IHC was also performed with antibodies against PTEN (clone 6H2.1, code M3627, Dako, at 1:200 dilution, for $30 \mathrm{~min}$ ), TopoIIa (clone Ki-S1, code M7186, Dako, at 1:200 dilution, for $30 \mathrm{~min}$ ) and phosphorylated mTOR at serine 2448 (p-mTOR, clone 49F9, code 2976, Cell Signaling Technology, at 1:30 dilution for $20 \mathrm{~min}$ ), using the Bond $\mathrm{Max}^{\mathrm{TM}}$ autostainer (Leica Microsystems, Wetzlar, Germany), as previously described in detail $(23,29)$. Sections were also stained with antibodies against IGF-1R $\alpha$ (clone 24-31, code MS-641-P, Thermo Scientific, Fremont, CA, at 1:50 dilution for $1 \mathrm{~h}$ ), IGF-1R $\beta$ (clone C-20, code sc-713, polyclonal antibody, raised against a peptide mapping at the C-terminus of the IGF-IR $\beta$ molecule, Santa Cruz Biotechnology, at 1:250 dilution for $1 \mathrm{~h}$ ) and IGF-2R (clone C-15, code sc-14410, goat polyclonal antibody, Santa Cruz Biotechnology, at 1:250 dilution for $1 \mathrm{~h}$ ), as previously described (30). All sections were stained in one run for each antibody and were evaluated by pathologists experienced in breast cancer and blinded as to the patient's clinical characteristics and survival data. Positive controls were used for all antibodies from known positive breast cancer cases, while negative controls were obtained by omitting the primary antibody, as previously described (22-25).

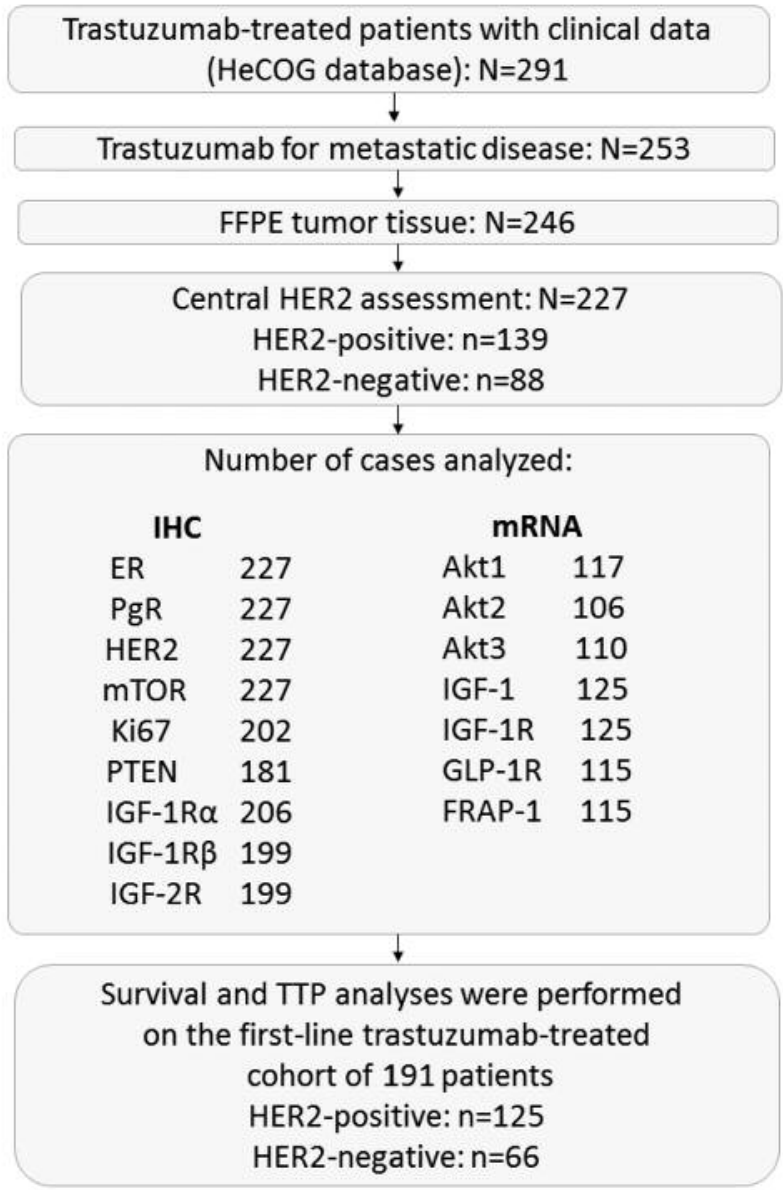

Figure 1. REMARK diagram.

Interpretation of $\mathrm{IHC}$ results. ER and PgR immunostaining was scored using the Histoscore method. Tumors were classified as ERor PgR-positive if staining was present in $1 \%$ or more of tumor nuclei (31). HER2 protein expression was scored according to the recent guideline recommendations (scores from 0 to $3+$ ) (32). PTEN protein expression (cytoplasmic, nuclear or both) was evaluated according to a staining intensity scale from 0 (negative, no staining) to 2 (intense staining). Tumors with PTEN scores of 0 or 1 were considered as having PTEN loss (33). For Ki67, the expression was defined as low $(<20 \%)$ or high $(\geq 20 \%)$ based on the percentage of stained versus unstained tumor cell nuclei (34). A tumor was considered positive for TopoIIa when moderate to intense nuclear staining was detected in $>5 \%$ of tumor cells (35). The phosphorylated form of mTOR at Ser2448, was defined as positive if at least mild cytoplasmic staining was detected in $>1 \%$ of tumor cells.

For the evaluation of IGF-1R $\alpha$, IGF-1R $\beta$ and IGF-2R proteins we used a semi-quantitative approach, based on staining intensity (SI) and percentage of positive cells (PP), to create the immunoreactive score (IRS) as follows: IRS=SI * PP, for each sample, as previously described (36). Intensity was scored as follows: $0=$ no staining, $1=$ weakly positive, $2=$ moderately positive and $3=$ strongly positive. The scoring of the staining pattern was 
A

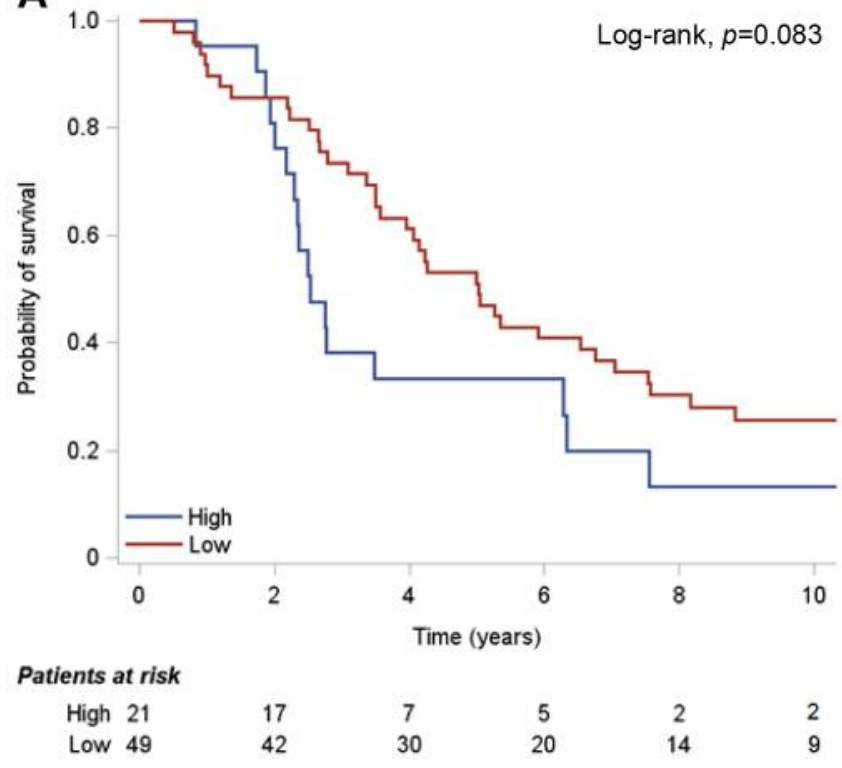

B

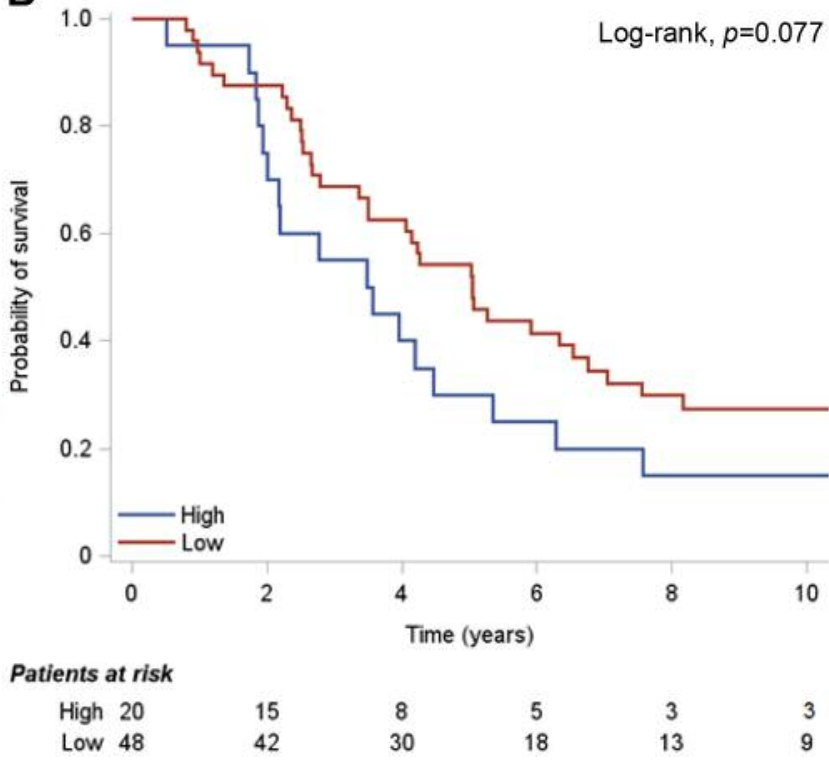

Figure 2. Kaplan-Meier curves for survival according to Akt1 mRNA expression (A) and GLP-1R mRNA expression (B) (using the upper quartile as a cut-off) in HER2-positive patients. Comparisons were estimated using the log-rank test.

based on the percentage of positive tumor cells: $0=0 \%, 1=0-9 \%$, $2=10-49 \%$ and $3=50-100 \%$. The IRS score thus ranged from 0 to 9 . The localization of staining for each protein was also indicated.

Fluorescence in situ hybridization (FISH). TMA sections or whole tissue sections ( $5 \mu \mathrm{m}$ thick) were used for FISH analysis using the ZytoLight ${ }^{\circledR}$ SPEC HER2/TOP2A/CEN17 triple color probe kit for HER2 (code Z-2093, ZytoVision, Bremerhaven, Germany). FISH was performed according to the manufacturer's protocol with minor modifications in all cases, not only the HER2 IHC 2+ cases. Digital images were constructed using specifically developed software for cytogenetics (XCyto-Gen, ALPHELYS, Plaisir, France), as previously described (22-25).

FISH evaluation. For the evaluation of HER2 gene status, 20 nonoverlapping nuclei from the invasive part of the tumor were selected randomly, according to morphological criteria using DAPI staining, and scored. The HER 2 gene was considered amplified when the ratio of the respective gene probe/centromere probe was $>2.2$ and deleted when the ratio was $\leq 0.75$ (32). In cases at or near the cutoff (1.8-2.2 for amplifications and 0.6-0.9 for deletions), additional 20 to 40 nuclei were counted and the ratio was recalculated. In cases with a borderline ratio from 60 nuclei, an additional FISH assay was performed in a whole section, as previously described in detail (28).

RNA isolation from FFPE tissue and quantitative reverse transcription-polymerase chain reaction ( $q R T-P C R)$ assessment. RNA was extracted from FFPE tissue sections, following histological examination to estimate tumor tissue abundance. In order to enrich the molecular template with tumor transcripts, manual macrodissection with a scalpel was performed in cases with $<50 \%$ tumor cell content. RNA extraction, from either whole or macrodissected $10 \mu \mathrm{m}$ paraffin sections, was carried out using a fully automated nucleic acid isolation method based on silica-coated magnetic beads (Versant Tissue Preparation Reagents, Siemens Healthcare Diagnostics, Tarrytown, NY, USA) in combination with a liquid handling robot (37). DNase I was added to each extract to remove DNA and ensure the presence of pure RNA for gene expression analyses. cDNA synthesis was performed with random primers and SuperScript ${ }^{\circledR}$ III Reverse Transcriptase (Invitrogen, Carlsbad, CA, cat. no. 48190011 and 18080044 , respectively), according to the manufacturer's instructions. cDNAs were assessed in duplicate $10 \mu \mathrm{l}$ reactions in 384-well plates with qRT-PCR in an ABI7900HT system for 45 cycles of amplification (default conditions).

The following exon-spanning premade Taqman-MGB assays (Applied Biosystems/Life Technologies) were selected for the transcripts under investigation (data in parentheses refer to assay ID; Genbank reference; amplicon location; size): IGF-1 (Hs00153126_m1; NM_000618.3, NM_001111283.1 and NM_001111285.1; exons 1-2; 70 bp), IGF-1R (Hs00609566_m1; NM_000875.3; exons 10-11; 64 bp), GLP-1R (Hs00157705_m1; NM_002062.3; exons 3-4; 78 bp), Akt1 (Hs00178289_m1; NM_001014431.1, NM_001014432.1 and NM_005163.2; exons 4-5 and 5-6; 66 bp), Akt2 (Hs00609846_m1; NM_001243027.1 andNM_001626.4; exons 1-2; 129 bp), Akt3 (Hs00178533_m1; NM_001206729.1, NM_005465.3, NM_181690.1 and NM_005465.3; exons 11-12 and 10-11; 100 bp) and FRAP-1 (mTOR) (Hs00234508_m1; NM_004958.3; exons 20-21; 103 bp).

A Taqman-MGB expression assay targeting $\beta$-glucuronidase (GUSB) mRNA (Hs00939627_m1; NM_000181.3; exons 8-9; 96 bp) was used for the assessment of relative quantification. GUSB was selected as the endogenous reference since, among the widely used housekeeping genes, it does not seem to be represented in pseudogenes. In addition, GUSB has been independently identified as one among the best-preserved mRNA targets in FFPE tissues (38, 
39). A commercially available reference RNA derived from multiple transformed cell lines (TaqMan ${ }^{\circledR}$ Control Total RNA, cat. no 4307281, Applied Biosystems, Foster City, CA, USA) was applied in multiple positions in each run, as positive control and for interrun evaluation of PCR assay efficiency. No-template controls were included. Samples were run in duplicates. To obtain linear relative quantification (RQ) values, relative expression was assessed as (40$\mathrm{dCT}$ ), whereby dCT (or delta cycle threshold, equivalent to $\mathrm{Cq}$ in MIQE guidelines) was calculated as (average target CT) - (average GUSB CT) from all eligible measurements. Samples were considered eligible when GUSB CT values were $<36$ and delta RQ values for each duplicate pair (intra-run variation) were $<0.8$. Interrun RQ values for the reference RNA were $<1$ for all assays.

Targeted PIK3CA mutation detection. DNA was extracted from 152 FFPE whole tissue sections or microdissected tissue fragments containing $>70 \%$ tumor cells, using a fully automated isolation method based on silica-coated magnetic beads (Versant Tissue Preparation Reagents, Siemens Healthcare Diagnostics) in combination with a liquid handling robot (37). Targeted mutation testing for PIK3CA E542K and E545K (exon 9) and H1047R (exon 20) was accomplished with custom Taqman-MGB-SNP genotyping assays (duplex qRT-PCR for the detection of control DNA and mutant target in the same reaction) in an ABI7500 sequence detection system equipped with the SDS v1.4 software (Applied Biosystems/Life technologies, Paisley, UK) opting for Allelic Discrimination, as previously described (22).

Statistical analysis. Follow-up information for all patients was updated in January 2017. Continuous variables are presented as medians with the corresponding range and categorical variables as frequencies with the respective percentages. Chi-square or Fisher's exact (where appropriate) tests were used for group comparisons of categorical data, while non-parametric Wilcoxon rank-sum tests were performed to detect differences between categorical and continuous variables. Associations between continuous variables were examined using Spearman correlations.

Time to progression (TTP) was defined as the time in months from the initiation of the trastuzumab first-line treatment (with or without simultaneous chemotherapy or hormonal therapy) to the date of documented disease progression. Patients who survived without relapse were censored at the date of their last contact. Survival was also measured from the initiation of trastuzumab firstline treatment to the date of death. Surviving patients were censored at the date of last contact. The Kaplan-Meier method was used for estimating time-to-event distributions, while log-rank tests were used for assessing statistically predefined comparisons. The 50th percentile (median value) was examined as the optimal cut-off in order to assess the prognostic significance of IGF-1, IGF-1R, GLP1R, Akt1, Akt2, Akt3 and FRAP-1 (mTOR) mRNA expression. In case the median value of the aforementioned markers was not significant, the upper and lower quartiles were assessed as possible cut-offs. The median value of the IRS was used as a cut-off to categorize the protein expression of IGF-1R $\alpha$, IGF-1R $\beta$ and IGF$2 \mathrm{R}$ proteins.

Univariate and multivariate Cox regression models were applied to identify significant prognostic factors of TTP and survival. The univariate and multivariate analyses were performed separately in HER2-positive and HER2-negative patients treated with trastuzumab in the first-line, respectively.
Table I. Selected patient and tumor characteristics by HER2 status.

\begin{tabular}{|c|c|c|c|}
\hline \multirow[b]{2}{*}{$\mathrm{N}$} & \multicolumn{3}{|c|}{ HER2 status } \\
\hline & $\begin{array}{l}\text { Total } \\
227\end{array}$ & $\begin{array}{l}\text { Negative } \\
88\end{array}$ & $\begin{array}{c}\text { Positive } \\
139\end{array}$ \\
\hline \multicolumn{4}{|l|}{ Age (years)^ } \\
\hline \multirow[t]{2}{*}{ Median (Range) } & $56.3(28.4-95)$ & $58.3(32-79)$ & $54.6(28.4-95)$ \\
\hline & $\mathrm{N}(\%)$ & $\mathrm{N}(\%)$ & $\mathrm{N}(\%)$ \\
\hline de novo $\mathrm{MBC}$ & $71(31.3)$ & $28(31.8)$ & $43(30.9)$ \\
\hline $\mathrm{R}-\mathrm{MBC}$ & $156(68.7)$ & $60(68.2)$ & $96(69.1)$ \\
\hline History of neoadjuvant $\mathrm{CT}^{*}$ & $15(9.6)$ & $6(10.0)$ & $9(9.4)$ \\
\hline History of adjuvant CT* & $127(81.4)$ & $50(83.3)$ & $77(80.2)$ \\
\hline Anthracycline-based CT* & $96(61.5)$ & $31(51.7)$ & $65(67.7)$ \\
\hline Taxane-containing $\mathrm{CT}^{*}$ & $54(34.6)$ & $16(26.7)$ & $38(39.6)$ \\
\hline CMF-based CT* & $73(46.8)$ & $29(48.3)$ & $44(45.8)$ \\
\hline History of adjuvant $\mathrm{HT}^{*}$ & $110(70.5)$ & $45(75.0)$ & $65(67.7)$ \\
\hline History of adjuvant RT* & $84(53.8)$ & $33(55.0)$ & $51(53.1)$ \\
\hline \multicolumn{4}{|l|}{$\begin{array}{l}\text { Number of } \\
\text { metastatic sites }\end{array}$} \\
\hline $1-3$ & $206(90.7)$ & $79(89.8)$ & $127(91.4)$ \\
\hline$\geq 4$ & $20(8.8)$ & $8(9.1)$ & $12(8.6)$ \\
\hline Unknown & $1(0.4)$ & $1(1.1)$ & $0(0.0)$ \\
\hline \multicolumn{4}{|l|}{ Histological grade } \\
\hline I-II & 95 (41.9) & $40(45.4)$ & $55(39.6)$ \\
\hline III & $117(51.5)$ & $41(46.6)$ & $76(54.6)$ \\
\hline Unknown & $15(6.6)$ & $7(8.0)$ & $8(5.8)$ \\
\hline \multicolumn{4}{|l|}{ Menopausal status^ } \\
\hline Premenopausal & $57(25.1)$ & $21(23.9)$ & $36(25.9)$ \\
\hline Postmenopausal & $168(74.0)$ & $67(76.1)$ & $101(72.7)$ \\
\hline Unknown & $2(0.9)$ & $0(0.0)$ & $2(1.4)$ \\
\hline \multicolumn{4}{|l|}{ Number of trastuzumab lines ${ }^{\wedge}$} \\
\hline 1 & $76(33.5)$ & $32(36.4)$ & $44(31.7)$ \\
\hline 2 & $54(23.8)$ & $21(23.7)$ & $33(23.7)$ \\
\hline 3 & $39(17.2)$ & $14(15.9)$ & $25(18.0)$ \\
\hline$\geq 4$ & $58(25.6)$ & $21(23.9)$ & $37(26.6)$ \\
\hline \multicolumn{4}{|l|}{ Performance status ${ }^{\wedge}$} \\
\hline 0 & $161(71.0)$ & $61(69.3)$ & $100(72.0)$ \\
\hline 1 & $52(22.9)$ & $20(22.7)$ & $32(23.0)$ \\
\hline 2 & $13(5.7)$ & $6(6.8)$ & $7(5.0)$ \\
\hline Unknown & $1(0.4)$ & $1(1.1)$ & $0(0.0)$ \\
\hline \multicolumn{4}{|l|}{ Subtype classification } \\
\hline Luminal A & $15(6.6)$ & $15(17.0)$ & $0(0.0)$ \\
\hline Luminal B & $53(23.3)$ & $53(60.2)$ & $0(0.0)$ \\
\hline Luminal-HER2 & $89(39.2)$ & $0(0.0)$ & $89(64.0)$ \\
\hline HER2-Enriched & $50(22.0)$ & $0(0.0)$ & $50(36.0)$ \\
\hline TNBC & $13(5.7)$ & $13(14.8)$ & $0(0.0)$ \\
\hline Unknown & $7(3.1)$ & $7(8.0)$ & $0(0.0)$ \\
\hline \multicolumn{4}{|l|}{ Sites of metastases ${ }^{\wedge}$} \\
\hline Locoregional & $76(33.5)$ & $28(31.8)$ & $48(34.5)$ \\
\hline Distant & $199(87.7)$ & $77(87.5)$ & $122(87.8)$ \\
\hline Only locoregional & $17(7.5)$ & $6(6.8)$ & $11(7.9)$ \\
\hline Only distant & $138(60.8)$ & $54(61.4)$ & $84(60.4)$ \\
\hline Bones & $96(42.3)$ & $40(45.5)$ & $56(40.3)$ \\
\hline Nodes & $44(19.4)$ & $15(17.0)$ & $29(20.9)$ \\
\hline Visceral & $150(66.1)$ & $53(60.2)$ & $97(69.8)$ \\
\hline
\end{tabular}

$\wedge$ At initiation of trastuzumab treatment; *Only for patients with relapsed metastatic breast cancer (R-MBC). HER2, human epidermal growth factor receptor 2; MBC, metastatic breast cancer; R-MBC, relapsed metastatic breast cancer; CT, chemotherapy; HT, hormonal therapy; RT, radiotherapy; CMF, cyclophosphamide/methotrexate/5 fluorouracil; TNBC, triple-negative breast cancer. 
Table II. Expression of the markers of interest by HER2 status.

\begin{tabular}{|c|c|c|c|c|c|}
\hline & & & \multicolumn{3}{|c|}{ HER2 status } \\
\hline & & & Negative & Positive & $p$-Value \\
\hline \multirow[t]{7}{*}{ Messenger RNA expression } & IGF-1 & Median (range) & $35.9(30.2-39.4)$ & $36.3(28.3-40.4)$ & $0.37^{\wedge}$ \\
\hline & IGF-1R & Median (range) & $42.0(33.9-45.0)$ & $41.2(37.1-44.6)$ & $0.19^{\wedge}$ \\
\hline & GLP-1R & Median (range) & $28.7(26.6-35.5)$ & $29.1(23.5-37.5)$ & $0.47^{\wedge}$ \\
\hline & Akt1 & Median (range) & $42.2(38.3-43.9)$ & $42.5(38.9-44.8)$ & $0.075^{\wedge}$ \\
\hline & Akt2 & Median (range) & $36.3(27.0-38.7)$ & $36.4(28.7-40.5)$ & $0.84^{\wedge}$ \\
\hline & Akt3 & Median (range) & $35.9(27.0-39.4)$ & $36.8(28.7-39.3)$ & $0.050^{\wedge}$ \\
\hline & & & $\mathrm{N}(\%)$ & $\mathrm{N}(\%)$ & \\
\hline \multirow[t]{10}{*}{ Protein expression } & Cytoplasmic IGF-1R $\alpha$ & Positive & $34(41.5)$ & $57(46.0)$ & $0.52 *$ \\
\hline & & Negative & $48(58.5)$ & $67(54.0)$ & \\
\hline & Cytoplasmic IGF-1R $\beta$ & Positive & $9(11.5)$ & $16(13.2)$ & $0.73 *$ \\
\hline & & Negative & $69(88.5)$ & $105(86.8)$ & \\
\hline & Stromal IGF-1R $\beta$ & Positive & 20 (25.6) & $33(27.3)$ & $0.80^{*}$ \\
\hline & & Negative & $58(74.4)$ & $88(72.7)$ & \\
\hline & Nuclear IGF-1R $\beta$ & Positive & $37(47.4)$ & $50(41.3)$ & $0.40^{*}$ \\
\hline & & Negative & $41(52.6)$ & $71(58.7)$ & \\
\hline & Cytoplasmic IGF-2R & Positive & $27(35.1)$ & 63 (51.6) & $0.022 *$ \\
\hline & & Negative & $50(64.9)$ & $59(48.4)$ & \\
\hline
\end{tabular}

${ }^{\wedge}$ Wilcoxon rank-sum test; $*$ Chi-square test.

In the multivariate analyses, model choice was performed using backward selection criteria with $p<0.10$, including the following clinicopathological parameters in the initial step: menopausal status (premenopausal vs. postmenopausal), ER/PgR status (negative $v s$. positive), performance status (1-2 vs. 0), number of metastatic sites ( $\geq 4$ vs. 1-3), PIK3CA status (mutated vs. wildtype), PTEN protein expression (no loss $v s$. loss), phosphorylated mTOR protein expression (positive $v s$. negative), as well as each of the markers that were found to be significant or revealed an indication towards statistical significance in the univariate analyses $(p<0.10)$.

Results of this study are presented according to reporting recommendations for tumor marker prognostic studies (40). All tests are two-sided at an alpha 5\% level of significance. Analyses were conducted using the SAS (version 9.3, SAS Institute Inc., Cary, NC, USA) software.

\section{Results}

A total of 227 patients with metastatic breast cancer, treated with trastuzumab were included in the current study. All of them were considered to have HER2-positive tumors, as assessed with IHC and FISH in some cases, by the investigators in the local hospitals/institutions. However, only 139 patients $(61.2 \%)$ were found to be truly HER2positive by central re-evaluation of HER2. Therefore, eightyeight patients $(38.8 \%)$ with HER2-negative tumors, treated with trastuzumab, were included in the study.

Table I presents basic patient and tumor characteristics by HER2-status. In total, seventy-one patients (31.3\%) were diagnosed with stage IV breast cancer (de novo $\mathrm{MBC}$ ), while
$68.7 \%$ of the study population was diagnosed at earlier stages of the disease (R-MBC). The median age at the initiation of trastuzumab therapy was 56.3 years, while the majority of R-MBC patients had been treated with adjuvant chemotherapy.

In total, 191 patients $(84.1 \%)$ received trastuzumab as firstline treatment (125 HER2-positive and 66 HER2-negative), while in $13.2 \%$ of patients trastuzumab was administered as a second-line therapy. The rest of the patients $(2.6 \%)$ received trastuzumab as third, fourth, fifth or sixth-line treatment. It is worth mentioning that in $89.4 \%$ of the study population, trastuzumab was administered with chemotherapy, while 19 patients $(8.4 \%)$ received trastuzumab in combination with hormonal therapy and in 5 patients $(2.2 \%)$ trastuzumab was administered as a monotherapy. Furthermore, 8 patients (3.5\%) had additionally received trastuzumab therapy in the adjuvant and/or neoadjuvant settings.

The distribution of all the examined markers by category and HER2 status for the entire study population is presented in Table II. HER2-positive patients presented with marginally significantly higher Akt 3 mRNA expression (Wilcoxon rank-sum, $p=0.050$ ), while positive cytoplasmic IGF-2R protein expression was more frequent in HER2positive patients as compared to patients with HER2negative tumors (Chi-square, $p=0.022$ ).

High mRNA expression of Akt1 and IGF-1R (using the median value as a cut-off) was associated with the luminal HER2 subtype (Chi-square, $p=0.037$ and $p<0.001$, respectively). In addition, high Aktl mRNA expression (using the lower quartile as a cut-off) was associated with 
Table III. Estimated hazard ratios (HR) and 95\% confidence intervals (CI) for survival and TTP in HER2-positive patients; results of the multivariate model.

$\begin{array}{lllll}\text { Categories } & \begin{array}{c}\mathrm{N} \text { of patients } \\ \mathrm{N} \text { of events }\end{array} & \text { HR } & 95 \% \mathrm{CI} & p \text {-Value }\end{array}$

Survival

Akt1 mRNA expression (using the upper quartile as a cut-off)

$\begin{array}{lllll}\text { High } v s . \text { Low } & 21 \text { vs. } 39 & 1.86 & 1.01-3.43 & 0.045 \\ & 17 v s .30 & & & \\ \text { High } v s . \text { Low } & 19 \text { vs. } 41 & 1.83 & 0.99-3.41 & 0.055 \\ & 17 v s .29 & & & \\ \text { High } v s . \text { Low } & 21 \text { vs. } 39 & 1.41 & 0.75-2.65 & 0.32 \\ & 17 v s .28 & & & \\ \text { High } v s . \text { Low } & 19 v s .41 & 1.47 & 0.75-2.89 & 0.26 \\ & 16 \text { vs. } 30 & & & \end{array}$

GLP-1R mRNA expression (using the upper quartile as a cut-off)

TTP

Akt1 mRNA expression (using the upper quartile as a cut-off)

GLP-1R mRNA expression (using the upper quartile as a cut-off)

16 vs. 30

$\mathrm{N}$, Number; HR, hazard ratio; CI, confidence interval.

age older than fifty years and no presence of nodal metastases ( $p=0.030$ and $p=0.036$, respectively). Low $A k t 2$ mRNA expression (using the upper quartile as a cut-off) was associated with absence of nodal metastases (Fisher's, $p=0.014$ ), while high $A k t 3$ mRNA expression (using the lower quartile as a cut-off) was associated with relapse in distant sites (Chi-square, $p=0.019$ ). High $I G F-1$ mRNA expression (using the lower quartile as a cut-off) was associated with older age ( $>50$ years) and absence of bone metastases (Fisher's $p=0.016$ and Chi-square, $p=0.041$, respectively). In contrast, low $I G F-1$ mRNA expression (using the median as a cut-off) was associated with histological grade III (Chi-square, $p=0.009$ ), distant metastases (Fisher's, $p=0.003$ ) and visceral metastases (Chisquare, $p=0.047$ ). Low $I G F-1 R$ mRNA expression (using the median as a cut-off) was more frequent in women of postmenopausal status $(p=0.006)$, higher histological grade (grade III) $(p=0.014)$ and older age $(p=0.009)$. High IGF- $1 R$ mRNA expression (using the median value as a cut-off) was associated with positive ER/PgR status, while high IGF-1R $\alpha$ protein expression was more frequent in patients with positive phosphorylated mTOR protein expression $(p=0.023)$. No significant associations were observed between the markers of interest and PTEN protein expression, while high IGF-1R $\beta$ protein expression was more frequently observed in women with positive TopoIIa protein expression $(p=0.024)$. In addition, a significant association was detected between high $I G F-1$ mRNA expression (using the median value as a cut-off) and wildtype PIK3CA $(p=0.033)$.

Associations between the markers of interest were examined separately in the subgroup of HER2-positive and HER2-negative patients. Among HER2-positive patients, IGF-1R was positively correlated with $A k t 1$ and $A k t 2$ mRNA expression (Spearman rho $=0.49, p<0.001$ and $r h o=0.51$, $p<0.001$, respectively), while a weak, positive correlation was observed between $I G F-1$ and $A k t 3$ mRNA expression $($ rho $=0.45, p<0.001)$. In addition, low nuclear IGF-1R $\beta$ protein expression was associated with low FRAP-1 (mTOR) mRNA expression (using the upper percentile as a cut-off) (Chi-square, $p=0.045)$. In HER2-negative patients, no significant correlations were observed between IGF and Akt mRNA expression, while high cytoplasmic protein expression of IGF1-R $\alpha$ was associated with high FRAP-1 (mTOR) mRNA expression (using the lower quartile as a cut-off) (Fisher's, $p=0.038$ ).

The median duration of follow-up was 138 (range 0.6192.6) and 126 (range 1.0-142.9) months for HER2-positive and HER2-negative patients who received trastuzumab as first-line treatment, respectively, while the median TTP was 15.3 months (range 0.6-192.6) and 10.4 months (range 1.6136.0) for HER2-positive and HER2-negative patients, respectively. Median survival of HER2 positive and HER2negative patients treated with trastuzumab in the first-line was 50.4 (range 0.6-192.6) and 38.1 months (range 4.5142.9), respectively. It is of note that no significant differences were detected between patients with HER2positive and HER2-negative tumors in terms of TTP and survival (log-rank, $p=0.15$ and $p=0.064$, respectively). In total, 152 patients treated with first-line trastuzumab (96 HER2-positive and 56 HER2-negative) died and 153 patients (98 HER2-positive and 58 HER2-negative) experienced a disease progression throughout the study. It should also be mentioned that 23 patients $(12.0 \%)$ treated with first-line trastuzumab regimens were reported dead within a year since the initiation of the treatment.

In the univariate analysis with respect to TTP, a trend towards increased risk of disease progression was observed for high Akt2 mRNA expression (using the lower quartile as a cut-off), while high GLP-1R mRNA expression (using the median as a cut-off) showed a significant trend associated with decreased risk of progression in the subgroup of 
patients with HER2-positive tumors that received trastuzumab as a first-line therapy $(\mathrm{HR}=1.83,95 \% \mathrm{CI}=0.90$ 3.72, Wald's $p=0.094$ and $\mathrm{HR}=0.62,95 \% \mathrm{CI}=0.36-1.06$, $p=0.079$, respectively). In terms of survival, a trend for increased risk of death was found for high Akt1 mRNA expression (using the upper quartile as a cut-off) and high GLP-1R mRNA expression (using the upper quartile as a cut-off $) \quad(\mathrm{HR}=1.67, \quad 95 \% \mathrm{CI}=0.93-2.99, \quad p=0.086$ and $\mathrm{HR}=1.67,95 \% \mathrm{CI}=0.94-2.96, p=0.080$, respectively) in HER2-positive patients (Figure 2).

Among HER2-negative patients treated with first-line trastuzumab, none of the examined markers reached any significance for TTP. Regarding survival, a trend towards increased risk of death was detected for high GLP-1R mRNA expression (using the lower quartile as a cut-off) and negative stromal IGF1-R $\beta$ protein expression $(\mathrm{HR}=2.31$, $95 \% \mathrm{CI}=0.87-6.13, p=0.094$ and $\mathrm{HR}=2.03,95 \% \mathrm{CI}=0.94-$ $4.35, p=0.071$, respectively). However, it should be mentioned that due to the limited number of fist-line HER2negative patients with available data regarding GLP-1R mRNA expression and stromal IGF1-R $\beta$ protein expression, there were only 5 patients with low GLP-IR mRNA expression and 9 patients with positive stromal IGF1-R $\beta$ protein expression that reported an event. Therefore, the aforementioned results should be interpreted with caution.

In the multivariate analyses, high Aktl mRNA expression (using the upper quartile as a cut-off) was a significant prognostic factor associated with worse survival in the HER2-positive population $(\mathrm{HR}=1.86,95 \% \mathrm{CI}=1.01-3.43$, Wald's $p=0.045$ ). In addition, HER2-positive patients with high $G L P-1 R$ mRNA expression (using the upper quartile as a cut-off) had marginally significant increased risk for death compared to patients with low GLP-1R mRNA expression (HR=1.83, 95\% CI=0.99-3.41, $p=0.055)$ (Table III). The rest of the markers that showed trends for survival or TTP in HER2-positive and HER2-negative patients did not demonstrate prognostic significance for TTP or survival in the multivariate analyses.

\section{Discussion}

In the present study, high Akt1 and GLP-1R mRNA expression was found to affect survival among HER2positive metastatic breast cancer patients treated with trastuzumab, indicating the existence of a crosstalk between the IGF-R pathway and HER2.

Preclinical studies suggest a role for IGF-1R signaling in trastuzumab resistance (41). Overexpression of IGF-1R prevents trastuzumab-mediated $\mathrm{G}_{1}$ arrest response in the SKBR3 cell line (12). In the MDA 231 breast cell line, treated with trastuzumab, down-regulation of IGF-1R is detected. When this cell line is chronically exposed to trastuzumab, resistant clones are developed, which shows a significantly higher expression of IGF-1R (42). IGF-1R expression is significantly upregulated in BT 474 trastuzumab-resistant cells compared to the trastuzumabsensitive parental BT 474 cell line (43).

Despite preclinical evidence, suggesting IGF-1R crosstalk with HER2 (12-14), in three clinical studies, no association was observed between IGF-1R expression alone and response to trastuzumab (44-46). However, when IGF-1R overexpression was combined with increased signaling of the mTOR pathway, resistance to trastuzumab was detected. In a recent study, overexpression of IGF-1R was associated with poor prognosis in HER2-positive breast cancer (47). Moreover, IGF-1R overexpression was associated with poor response to neoadjuvant trastuzumab and vinorelbine (48). In another study among 67 patients with early breast cancer and 75 patients with metastatic disease, all with HER2positive disease, IGF-1R staining was high in $25 \%$ of the tumors and was significantly associated with high grade, high mitotic index and vascular invasion (14). In the metastatic disease patients of the above cohort, increased PI3K signaling was associated with decreased PFS.

In our study, cytoplasmic IGF-1R $\alpha$ staining was positive in $41.5 \%$ of HER2-negative tumors and $46.0 \%$ of HER2positive tumors. IGF-IR mRNA was associated with Aktl and $A k t 2$ mRNA expression, while low nuclear IGF-1R $\beta$ protein expression was associated with low FRAP-1 (mTOR) mRNA expression in HER2-positive tumors, suggesting activation of the Akt/mTOR pathway.

High levels of $I G F-1 R$ mRNA expression were associated with hormone receptor-positive disease, whereas low levels were related to hormone receptor-negative breast cancer subtypes (HER2-enriched, TNBC). These results are in line with the study of Shin et al. (49) suggesting a close relation between hormonal receptor status and IGF-1 expression. In a recent study, performed by our group, IGF-1R $\alpha$ was consistently overexpressed in all ER/PgR-positive tumors, including the luminal-HER2 subtype (30). That study referred to patients with early breast cancer, while the current study included patients with metastatic disease, indicating a continuous relation, irrespectively of stage of disease.

In another recent study performed by our group, it was shown that PIK3CA-activating mutations were associated with shorter TTP and PTEN loss with decreased survival among HER2-positive patients treated with trastuzumab (22). Moreover, it was demonstrated that the activation of the PI3K/Akt pathway from either defect was associated with both TTP and survival, indicating resistance to the treatment with trastuzumab. In the current study, we reveal that overexpression of IGF- $1 \mathrm{R} \alpha$ or IGF- $1 \mathrm{R} \beta$ protein expression is associated with activation of the Akt/mTOR pathway. Similarly, high levels of IGF-1R mRNA expression activate the same pathway among HER2-positive patients treated with trastuzumab. 
In our study, among patients with HER2-positive tumors treated with trastuzumab, a trend towards increased risk of disease progression was detected for high Akt2 mRNA expression and a trend associated with worse survival for high Akt1 and GLP-1R mRNA expression, which reached significance for survival in the multivariate model, a finding that appears to suggest that activation of the Akt/mTOR pathway is a mechanism of resistance to trastuzumab.

Preclinical studies have shown that dual inhibition of both IGF-1R and mTOR results in an additive effect, while this combination was further tested in phase I/II studies (50). A phase II clinical trial with the IGF-R monoclonal antibody cixutumumab added to capecitabine and lapatinib, though, failed to show improvement in PFS in HER2-positive breast cancer patients (51). Nevertheless, the mechanism of reversing trastuzumab resistance with mTOR inhibitors still remains unclear.

In conclusion, this study showed a crosstalk between the IGF-R pathway and HER2. There was evidence that high $A k t 1$ and $G L P-1 R$ mRNA expression might affect survival among HER2-positive metastatic breast cancer patients treated with trastuzumab. However, our results revealed mostly trends towards significance for TTP and survival, which could be attributed to the small number of patients with available data in some of our comparisons. Another important limitation of our findings is that they were not obtained within a randomized setting and should, therefore, be interpreted with caution.

\section{Conflicts of Interest}

C. Christodoulou: Advisory Role: Merck, Zeincro, Genesis Pharmaceuticals, Pfizer, Novartis, Roche, AstraZeneca, Bristol Myers Squibbs. Honoraria: Roche, Bristol Myers Squibbs. Research funding: Abbvie, PPD, Inc., Novartis, Parexel, AstraZeneca.

A. Koutras: Advisory Role: Roche, Genesis, Astra-Zeneca, Travel: Novartis, Merck, Sanofi-Aventis, Astellas, Genesis, BMS, Pfizer

E. Razis: Advisory Role: Roche, Amgen, AstraZeneca, JanssenCilag, Astellas Pharma, Novartis, Bristol-Myers Squibb, Merck, Pfizer, Zeincro, Travel: Genesis Pharmaceuticals, LEO Pharma, Pfizer, Roche, GlaxoSmithKline, Sanofi, Amgen, Bristol-Myers Squibb, Genekor, Eisai, Merck, Pierre Fabre, Novartis, Honoraria: Roche, AstraZeneca, GlaxoSmithKline, Amgen, Novartis, Zeincro, Merck, Pfizer, BristolMyers Squibb, Research Funding: Sanofi, Roche/Genentech, Novartis, AstraZeneca, Demo Pharmaceutical, Celldex, Parexel

P. Papakostas: Advisory Role: Roche, Merck, Genesis Pharmaceuticals, Honoraria: Roche, Merck

G. Fountzilas: Advisory Role: Pfizer, Sanofi and Roche. Honoraria: Astra-Zeneca.

\section{Acknowledgements}

The Authors would like to thank Dimitra Katsala for monitoring the study and Maria Moschoni for coordinating the data management. The study was supported by a Hellenic Cooperative Oncology Group grant HER_11P/05 and a research grant from Roche Hellas
SA. The funders had no role in the study design, data collection and analysis, decision to publish, or preparation of the manuscript.

\section{References}

1 Slamon DJ, Clark GM, Wong SG, Levin WJ, Ullrich A and McGuire WL: Human breast cancer: Correlation of relapse and survival with amplification of the her-2/neu oncogene. Science 235(4785): 177-182, 1987.

2 Nguyen PL, Taghian AG, Katz MS, Niemierko A, Abi Raad RF, Boon WL, Bellon JR, Wong JS, Smith BL and Harris JR: Breast cancer subtype approximated by estrogen receptor, progesterone receptor, and her-2 is associated with local and distant recurrence after breast-conserving therapy. J Clin Oncol 26(14): 2373-2378, 2008.

3 Murphy CG and Modi S: Her2 breast cancer therapies: A review. Biologics 3: 289-301, 2009.

4 Viani GA, Afonso SL, Stefano EJ, De Fendi LI and Soares FV: Adjuvant trastuzumab in the treatment of her-2-positive early breast cancer: A meta-analysis of published randomized trials. BMC Cancer 7: 153, 2007.

5 Vogel CL, Cobleigh MA, Tripathy D, Gutheil JC, Harris LN, Fehrenbacher L, Slamon DJ, Murphy M, Novotny WF, Burchmore M, Shak S, Stewart SJ and Press M: Efficacy and safety of trastuzumab as a single agent in first-line treatment of her2-overexpressing metastatic breast cancer. J Clin Oncol 20(3): 719-726, 2002.

6 Marty M, Cognetti F, Maraninchi D, Snyder R, Mauriac L, Tubiana-Hulin M, Chan S, Grimes D, Anton A, Lluch A, Kennedy J, O'Byrne K, Conte P, Green M, Ward C, Mayne K and Extra JM: Randomized phase ii trial of the efficacy and safety of trastuzumab combined with docetaxel in patients with human epidermal growth factor receptor 2-positive metastatic breast cancer administered as first-line treatment: The $\mathrm{m} 77001$ study group. J Clin Oncol 23(19): 4265-4274, 2005.

7 Nahta R, Yu D, Hung MC, Hortobagyi GN and Esteva FJ: Mechanisms of disease: Understanding resistance to her2targeted therapy in human breast cancer. Nat Clin Pract Oncol 3(5): 269-280, 2006

8 Nahta R: Pharmacological strategies to overcome her2 cross-talk and trastuzumab resistance. Curr Med Chem 19(7): 1065-1075, 2012.

9 Luque-Cabal M, Garcia-Teijido P, Fernandez-Perez Y, SanchezLorenzo L and Palacio-Vazquez I: Mechanisms behind the resistance to trastuzumab in her2-amplified breast cancer and strategies to overcome it. Clin Med Insights Oncol 10(Suppl 1): 21-30, 2016.

10 Ekyalongo RC and Yee D: Revisiting the igf-1r as a breast cancer target. npj Precision Oncology 1(1): 14, 2017.

11 Kar A, Liu B and Gutierrez-Hartmann A: Ese-1 knockdown attenuates growth in trastuzumab-resistant her2(+) breast cancer cells. Anticancer Res 37(12): 6583-6591, 2017.

12 Lu Y, Zi X, Zhao Y, Mascarenhas D and Pollak M: Insulin-like growth factor-i receptor signaling and resistance to trastuzumab (herceptin). J Natl Cancer Inst 93(24): 1852-1857, 2001.

13 Nahta R, Yuan LX, Zhang B, Kobayashi R and Esteva FJ: Insulin-like growth factor-i receptor/human epidermal growth factor receptor 2 heterodimerization contributes to trastuzumab resistance of breast cancer cells. Cancer Res 65(23): 1111811128, 2005. 
14 Gallardo A, Lerma E, Escuin D, Tibau A, Munoz J, Ojeda B, Barnadas A, Adrover E, Sanchez-Tejada L, Giner D, OrtizMartinez F and Peiro G: Increased signalling of egfr and igf1r, and deregulation of pten/pi3k/akt pathway are related with trastuzumab resistance in her 2 breast carcinomas. Br J Cancer 106(8): 1367-1373, 2012.

15 Surmacz E: Growth factor receptors as therapeutic targets: Strategies to inhibit the insulin-like growth factor i receptor. Oncogene 22(42): 6589-6597, 2003.

16 Werner $\mathrm{H}$ and Bruchim I: The insulin-like growth factor-i receptor as an oncogene. Arch Physiol Biochem 115(2): 58-71, 2009.

17 Pollak M: The insulin and insulin-like growth factor receptor family in neoplasia: An update. Nat Rev Cancer 12(3): 159-169, 2012.

18 Christopoulos PF, Msaouel P and Koutsilieris M: The role of the insulin-like growth factor- 1 system in breast cancer. Mol Cancer 14: 43, 2015.

19 Hartog H, Van Der Graaf WT, Boezen HM and Wesseling J: Treatment of breast cancer cells by igf1r tyrosine kinase inhibitor combined with conventional systemic drugs. Anticancer Res 32(4): 1309-1318, 2012.

20 Haisa M: The type 1 insulin-like growth factor receptor signalling system and targeted tyrosine kinase inhibition in cancer. J Int Med Res 41(2): 253-264, 2013.

21 Vincent AM and Feldman EL: Control of cell survival by igf signaling pathways. Growth Horm IGF Res 12(4): 193-197, 2002.

22 Razis E, Bobos M, Kotoula V, Eleftheraki AG, Kalofonos HP, Pavlakis K, Papakostas P, Aravantinos G, Rigakos G, Efstratiou I, Petraki K, Bafaloukos D, Kostopoulos I, Pectasides D, Kalogeras KT, Skarlos D and Fountzilas G: Evaluation of the association of pik3ca mutations and pten loss with efficacy of trastuzumab therapy in metastatic breast cancer. Breast Cancer Res Treat 128(2): 447-456, 2011.

23 Fountzilas G, Christodoulou C, Bobos M, Kotoula V, Eleftheraki AG, Xanthakis I, Batistatou A, Pentheroudakis G, Xiros N, Papaspirou I, Koumarianou A, Papakostas P, Bafaloukos D, Skarlos DV and Kalogeras KT: Topoisomerase ii alpha gene amplification is a favorable prognostic factor in patients with her2-positive metastatic breast cancer treated with trastuzumab. J Transl Med 10: 212, 2012.

24 Pavlakis K, Bobos M, Batistatou A, Kotoula V, Eleftheraki AG, Stofas A, Timotheadou E, Pentheroudakis G, Psyrri A, Koutras A, Pectasides D, Papakostas P, Razis E, Christodoulou C, Kalogeras KT and Fountzilas G: P85 protein expression is associated with poor survival in her2-positive patients with advanced breast cancer treated with trastuzumab. Pathol Oncol Res 21(2): 273-282, 2015.

25 Koumarianou A, Karayannopoulou G, Gourgioti G, Batistatou A, Bobos M, Efstratiou I, Miliaras D, Galani E, Pentheroudakis G, Pectasides D, Aravantinos G, Bafaloukos D, Papakostas P, Razis E, Kalofonos HP, Petraki K, Sotiropoulou M, Kalogeras KT and Fountzilas G: Pai-1 and her2 interaction in advanced breast cancer disease: Evidence for added benefit from trastuzumab in her2-negative patients. Cancer Chemother Pharmacol 75(6): 1289-1301, 2015.

26 Gogas H, Kotoula V, Alexopoulou Z, Christodoulou C, Kostopoulos I, Bobos M, Raptou G, Charalambous E, Tsolaki E, Xanthakis I, Pentheroudakis G, Koutras A, Bafaloukos D, Papakostas P, Aravantinos G, Psyrri A, Petraki K, Kalogeras KT,
Pectasides D and Fountzilas G: Myc copy gain, chromosomal instability and pi3k activation as potential markers of unfavourable outcome in trastuzumab-treated patients with metastatic breast cancer. J Transl Med 14(1): 136, 2016.

27 Furrer D, Jacob S, Caron C, Sanschagrin F, Provencher L and Diorio C: Concordance of her2 immunohistochemistry and fluorescence in situ hybridization using tissue microarray in breast cancer. Anticancer Res 37(6): 3323-3329, 2017.

28 Skarlos P, Christodoulou C, Kalogeras KT, Eleftheraki AG, Bobos M, Batistatou A, Valavanis C, Tzaida O, Timotheadou E, Kronenwett R, Wirtz RM, Kostopoulos I, Televantou D, Koutselini E, Papaspirou I, Papadimitriou CA, Pectasides D, Gogas H, Aravantinos G, Pavlidis N, Arapantoni P, Skarlos DV and Fountzilas G: Triple-negative phenotype is of adverse prognostic value in patients treated with dose-dense sequential adjuvant chemotherapy: A translational research analysis in the context of a hellenic cooperative oncology group (hecog) randomized phase iii trial. Cancer Chemother Pharmacol 69(2): 533-546, 2012.

29 Lazaridis G, Lambaki S, Karayannopoulou G, Eleftheraki AG, Papaspirou I, Bobos M, Efstratiou I, Pentheroudakis G, Zamboglou N and Fountzilas G: Prognostic and predictive value of p-akt, egfr, and p-mtor in early breast cancer. Strahlenther Onkol 190(7): 636-645, 2014.

30 Mountzios G, Aivazi D, Kostopoulos I, Kourea HP, Kouvatseas G, Timotheadou E, Zebekakis P, Efstratiou I, Gogas H, Vamvouka C, Chrisafi S, Stofas A, Pentheroudakis G, Koutras A, Galani E, Bafaloukos D and Fountzilas G: Differential expression of the insulin-like growth factor receptor among early breast cancer subtypes. PLoS One 9(3): e91407, 2014.

31 Hammond ME, Hayes DF, Dowsett M, Allred DC, Hagerty KL, Badve S, Fitzgibbons PL, Francis G, Goldstein NS, Hayes M, Hicks DG, Lester S, Love R, Mangu PB, McShane L, Miller K, Osborne CK, Paik S, Perlmutter J, Rhodes A, Sasano H, Schwartz JN, Sweep FC, Taube S, Torlakovic EE, Valenstein P, Viale G, Visscher D, Wheeler T, Williams RB, Wittliff JL and Wolff AC: American society of clinical oncology/college of american pathologists guideline recommendations for immunohistochemical testing of estrogen and progesterone receptors in breast cancer. $\mathbf{J}$ Clin Oncol 28(16): 2784-2795, 2010.

32 Wolff AC, Hammond ME, Schwartz JN, Hagerty KL, Allred DC, Cote RJ, Dowsett M, Fitzgibbons PL, Hanna WM, Langer A, McShane LM, Paik S, Pegram MD, Perez EA, Press MF, Rhodes A, Sturgeon C, Taube SE, Tubbs R, Vance GH, van de Vijver M, Wheeler TM and Hayes DF: American society of clinical oncology/college of american pathologists guideline recommendations for human epidermal growth factor receptor 2 testing in breast cancer. J Clin Oncol 25(1): 118-145, 2007.

33 Fountzilas G, Bobos M, Kalogera-Fountzila A, Xiros N, Murray S, Linardou H, Karayannopoulou G, Koutras AK, Bafaloukos D, Samantas E, Christodoulou C, Economopoulos T, Kalogeras KT and Kosmidis P: Gemcitabine combined with gefitinib in patients with inoperable or metastatic pancreatic cancer: A phase ii study of the hellenic cooperative oncology group with biomarker evaluation. Cancer Invest 26(8): 784793, 2008.

34 Romero Q, Bendahl PO, Ferno M, Grabau D and Borgquist S: A novel model for ki67 assessment in breast cancer. Diagn Pathol 9: 118, 2014. 
35 Bhargava R, Lal P and Chen B: Her-2/neu and topoisomerase iia gene amplification and protein expression in invasive breast carcinomas: Chromogenic in situ hybridization and immunohistochemical analyses. Am J Clin Pathol 123(6): 889895, 2005.

36 Diallo-Danebrock R, Ting E, Gluz O, Herr A, Mohrmann S, Geddert H, Rody A, Schaefer KL, Baldus SE, Hartmann A, Wild PJ, Burson M, Gabbert HE, Nitz U and Poremba C: Protein expression profiling in high-risk breast cancer patients treated with high-dose or conventional dose-dense chemotherapy. Clin Cancer Res 13(2 Pt 1): 488-497, 2007.

37 Bohmann K, Hennig G, Rogel U, Poremba C, Mueller BM, Fritz P, Stoerkel S and Schaefer KL: Rna extraction from archival formalin-fixed paraffin-embedded tissue: A comparison of manual, semiautomated, and fully automated purification methods. Clin Chem 55(9): 1719-1727, 2009.

38 Zhang F, Wang ZM, Liu HY, Bai Y, Wei S, Li Y, Wang M, Chen $\mathrm{J}$ and Zhou QH: Application of rt-pcr in formalin-fixed and paraffin-embedded lung cancer tissues. Acta Pharmacol Sin 31(1): 111-117, 2010.

39 Sanchez-Navarro I, Gamez-Pozo A, Gonzalez-Baron M, PintoMarin A, Hardisson D, Lopez R, Madero R, Cejas P, Mendiola $\mathrm{M}$, Espinosa $\mathrm{E}$ and Vara JA: Comparison of gene expression profiling by reverse transcription quantitative pcr between freshfrozen and formalin-fixed, paraffin-embedded breast cancer tissues. Biotechniques 48(5): 389-397, 2010.

40 McShane LM, Altman DG, Sauerbrei W, Taube SE, Gion M, Clark GM and Statistics Subcommittee of the NCIEWGoCD: Reporting recommendations for tumor marker prognostic studies. J Clin Oncol 23(36): 9067-9072, 2005.

41 Alexander PB, Chen R, Gong C, Yuan L, Jasper JS, Ding Y, Markowitz GJ, Yang P, Xu X, McDonnell DP, Song E and Wang XF: Distinct receptor tyrosine kinase subsets mediate anti-her2 drug resistance in breast cancer. J Biol Chem 292(2): 748-759, 2017.

42 Cornelissen B, McLarty K, Kersemans V and Reilly RM: The level of insulin growth factor- 1 receptor expression is directly correlated with the tumor uptake of (111)in-igf-1(e3r) in vivo and the clonogenic survival of breast cancer cells exposed in vitro to trastuzumab (herceptin). Nucl Med Biol 35(6): 645-653, 2008.

43 Jerome L, Alami N, Belanger S, Page V, Yu Q, Paterson J, Shiry L, Pegram $M$ and Leyland-Jones B: Recombinant human insulin-like growth factor binding protein 3 inhibits growth of human epidermal growth factor receptor-2-overexpressing breast tumors and potentiates herceptin activity in vivo. Cancer Res 66(14): 7245-7252, 2006.

44 Smith BL, Chin D, Maltzman W, Crosby K, Hortobagyi GN and Bacus SS: The efficacy of herceptin therapies is influenced by the expression of other erbb receptors, their ligands and the activation of downstream signalling proteins. Br J Cancer 91(6): 1190-1194, 2004.
45 Kostler WJ, Hudelist G, Rabitsch W, Czerwenka K, Muller R, Singer CF and Zielinski CC: Insulin-like growth factor-1 receptor (igf-1r) expression does not predict for resistance to trastuzumab-based treatment in patients with her-2/neu overexpressing metastatic breast cancer. J Cancer Res Clin Oncol 132(1): 9-18, 2006.

46 Reinholz MM, Chen B, Dueck AC, Tenner K, Ballman K, Riehle D, Jenkins RB, Geiger XJ, McCullough AE and Perez EA: Igf1r protein expression is not associated with differential benefit to concurrent trastuzumab in early-stage her $2+$ breast cancer from the north central cancer treatment group (alliance) adjuvant trastuzumab trial n9831. Clin Cancer Res 23(15): 4203-4211, 2017.

47 Yerushalmi R, Gelmon KA, Leung S, Gao D, Cheang M, Pollak M, Turashvili G, Gilks BC and Kennecke H: Insulin-like growth factor receptor (igf-1r) in breast cancer subtypes. Breast Cancer Res Treat 132(1): 131-142, 2012.

48 Harris LN, You F, Schnitt SJ, Witkiewicz A, Lu X, Sgroi D, Ryan PD, Come SE, Burstein HJ, Lesnikoski BA, Kamma M, Friedman PN, Gelman R, Iglehart JD and Winer EP: Predictors of resistance to preoperative trastuzumab and vinorelbine for her2-positive early breast cancer. Clin Cancer Res 13(4): 11981207, 2007.

49 Shin SJ, Gong G, Lee HJ, Kang J, Bae YK, Lee A, Cho EY, Lee JS, Suh KS, Lee DW and Jung WH: Positive expression of insulin-like growth factor- 1 receptor is associated with a positive hormone receptor status and a favorable prognosis in breast cancer. J Breast Cancer 17(2): 113-120, 2014.

50 Di Cosimo S and Baselga J: Targeted therapies in breast cancer: Where are we now? Eur J Cancer 44(18): 2781-2790, 2008.

51 Haluska P, Bernath AM, Ballman KV, Dueck AC, Linden HM, Goetz MP, Northfelt DW, Hou X, Tenner KS, Tienchaiananda P, Flickinger LM, Chen B, Chen HX, Lingle WL, Pellegrino CM, Sponzo RW, Reinholz MM, Perez EA and Oncology AfCTi: Randomized phase ii trial of capecitabine and lapatinib with or without cixutumumab in patients with her2+ breast cancer previously treated with trastuzumab and an anthracycline and/or a taxane: Ncctg n0733 (alliance). J Clin Oncol 32(15 suppl): 632, 2014.
Received March 27, 2018

Revised August 29, 2018 Accepted September 12, 2018 